\title{
Genetic Architecture of Grain Chalk in Rice and Interactions with a Low Phytic Acid Locus
}

Jeremy D. Edwards*, Aaron K. Jackson, and Anna M. McClung

J.D. Edwards*, A.K. Jackson, and A.M.McClung, USDA-ARS Dale Bumpers National Rice Research Center, 2890 Highway 130 East, Stuttgart, AR 72160

*Corresponding author (jeremy.edwards@ars.usda.gov

\section{) .}

Key Words: Oryza sativa L., Rice, Milling Quality, Grain Chalk, Grain Width, Low Phytic Acid, QTL

Abbreviations: cM, centimorgans; MAS, marker-assisted selection; Mb, megabase pairs in reference to physical location along a chromosome; QTL, quantitative trait locus; SNP, single nucleotide polymorphism; SSR, simple sequence repeat.

\section{Acknowledgments:}

This research utilized facilities and assistance provided by USDA Agricultural Research Service Dale Bumpers National Rice Research Center. The authors acknowledge Laduska Sells, Tiffany Sookaserm, Tyler Teske, and Jeremy Kite for conducting the field experiments and grain imaging, Dr. Kathleen Yeater for initial statistical consultation, Brenda Lawrence for DNA extractions, and Lorie Bernhardt for compiling weather data. USDA is an equal opportunity provider and employer. 


\section{ABSTRACT}

Grain quality characteristics have a major impact on the value of the harvested rice

3 crop. In addition to grain dimensions which determine rice grain market classes, translucent

4 milled kernels are also important for assuring the highest grain quality and crop value. Over the

5 last several years, there has been increasing concern by the rice industry regarding prevalence

6 of chalky grains which are resulting in a loss of some markets. This study was conducted to

7 identify genetic markers associated with grain chalk that could be used by breeders to develop

8 new varieties that have translucent grains across different environments. A mapping population

9 developed from KBNT-1-1, a translucent, low phytic acid (LPA) mutant derived from the US long

10 grain variety Kaybonnet, crossed with Zhe733, a chalky, long grain variety developed in China,

11 was evaluated in replicated trials conducted across two years and two planting dates that

12 differed by one month. The progeny were evaluated for days to flowering in the field. Grain was

13 harvested at maturity and brown or milled rice were used to determine grain length, width, and

14 percent chalk using an image analysis system. The 187 F12 progeny were evaluated using 174

15 genome-wide microsatellite markers and one SNP marker, and QTL analysis was performed. A

16 large effect QTL was co-located with the LPA gene, and the mutated KBNT-1-1 LPA allele was

17 associated with increased chalk suggesting that low phytic acid may be one cause of chalk in

18 this cross. Nine additional QTL were detected with the KBNT-1-1 allele associated with reduced

19 chalk and one with increased chalk. Overlaps were identified between chalk QTL, candidate

20 genes for chalk, and QTL for other traits such as grain width. Measures of night temperature

21 and humidity experienced during grain filling were positively correlated with increased chalk.

22 Year and planting time were also shown to significantly affect chalk. However there was no 
23 interaction with the pattern of QTL detected and any of the environmental differences,

24 indicating that these QTL are robust across diverse growing conditions.

25 
INTRODUCTION

The degree of chalkiness in rice affects grain quality and milling yield. Chalk negatively

28 impacts cooking quality characteristics, such as texture and palatability which subsequently

29 reduces the market value of rice (Chun et al., 2009; Lisle et al., 2000). The presence of chalk also

30 negatively impacts milling yield by increasing the number of broken kernels, which in turn

31 reduces the proportion of whole kernels (Khush et al., 1979). The frequent breakage during

32 milling of chalky rice is caused by less densely packed starch granules in the chalky areas and

33 less hardness than the translucent areas of the grain (Del Rosario et al., 1968). Broken grains

34 sell for a lower price than unbroken (head rice); over the last ten years the world market price

35 of broken rice has fluctuated between 35 to almost $50 \%$ less than that of head rice (Childs,

36 2016). Reduced milling yield can be especially problematic with long grain rice varieties as

37 their greater length to width ratio makes them more susceptible to grain structure

38 inconsistencies caused by chalk (Wan et al., 2005). In the USA, over $70 \%$ of the rice grown in

392015 consisted of long grain varieties (Childs, 2016) and thus, it becomes critical to understand

40 and manage grain chalk that can significantly reduce milling yield.

41 Chalk is influenced by the environment and genetics. Higher temperatures, and

42 particularly higher night air temperatures (NTAT) during grain filling, significantly increase chalk

43 (Ambardekar et al., 2011; Counce et al., 2005; Lanning et al., 2011). There is a positive

44 quadratic relationship between the 95th percentiles of the NTAT frequencies (NT 95 ) occurring

45 during the grain filling stage and the degree of chalk. The amount of chalk is also strongly

46 affected by variety and there is a differential response to increased NT95 between varieties 
47 (Ambardekar et al., 2011). High quality rice varieties have been developed to have low chalk,

48 an important factor in grain grading. However, when genetically diverse lines are used as

49 parents in rice hybrids to increase yield through heterosis, or when exotic varieties are used as

50 donors to introgress alleles for improved stress resistance or agronomic traits, there is a

51 potential to increase chalk and reduce grain quality. Thus, it is critical to understand the

52 genetic factors that affect chalk to be able to make full use of rice genetic diversity for variety

53 development while sustaining grain quality in competitive commercial markets.

Chalk in rice occurs as an opaque white discoloration in the endosperm or as localized

55 patches in the center, back or throughout the grain (Ashida et al., 2009). Chalky endosperm

56 contains amyloplasts with a more rounded appearance and a disordered cellular structure than

57 in translucent endosperm . Inside chalky grains the amyloplasts contain small loosely packed

58 starch granules with greater airspace between them (Chun et al., 2009; Lisle et al., 2000). The

59 airspaces hinder the transmission of light resulting in the characteristic opaque chalky

60 appearance, as well as creating mechanical weaknesses within the cellular structure of the rice

61 grain, which in turn may increase the incidence of breakage during milling (Kepiro et al., 2008).

63 involved in the deposition of storage components during the source/sink process of grainfill,

64 which in turn affects chalk formation in the developing grain. Li et al. (2014) recently cloned

65 Chalk5, which encodes a vacuolar $\mathrm{H}_{+}$-translocating pyrophosphatase (V-PPase). Over expression

66 of Chalk5 is believed to contribute to chalk formation by disturbing $\mathrm{pH}$ homeostasis of the

67 endomembrane trafficking system and interfering with the biogenesis of protein bodies during

68 endosperm development. This in turn leads to the formation of airspaces around starch 
69 granules and protein bodies (Li et al., 2014). Other studies have implicated amylose, starch

70 biosynthesis and starch structure as components of chalk formation. Patindol and Wang (2003)

71 performed an analysis of the starch content of chalky kernels and found a greater abundance of

72 amylopectin with long branch chains, and a decrease in overall amylose content. A microarray

73 study performed by Yamakawa et al. (2007) exposed developing rice grains to high

74 temperatures during the milky stage. They found high temperatures caused down regulation of

75 starch branching enzymes (particularly branching enzyme Ilb), granule-bound starch synthase I

76 and cytosolic pyruvate orthophosphate dikinase while enzymes involved in starch degradation

77 such as $\alpha$-amylase and heat shock proteins were up regulated.

78 A review paper by Sreenivasulu et al. (2015) reports over 140 quantitative trait loci

79 (QTL) related to chalkiness have been identified spanning all 12 twelve chromosomes in rice. A

80 wide range of genes involved with starch formation and storage protein regulation have been

81 implicated in grain chalk. Biparental mapping populations have identified QTL responsible for

82 chalk at or near genes such as Waxy, starch synthase III A, pyruvate orthosphosphate dikinase,

83 UDP glucose pyrophosphatase, cell wall invertase, and $H_{+}$-translocating pyrophosphatases

84 (Fujita et al., 2007; Kang et al., 2005; Li et al., 2014; Peng et al., 2014; Wang et al., 2008; Woo et

85 al., 2008). Sreenivasulu et al. (2015) point out that QTL studies combined with transcriptome

86 analysis suggest that many high temperature response pathways involved with starch and

87 storage protein metabolism during grain development are co-located with chalk QTL. Storage

88 proteins levels have also been shown to be influenced by higher temperatures during different

89 stages of seed development, which in turn may contribute to the formation of chalk (Li et al.,

90 2011). 
92 recombinant inbred lines (RIL's) of the Kaybonnet low phytic acid mutant, KBNT-1-1,

93 (henceforth referred to as KBNT Ipa) X Zhe733. The KBNT Ipa parent was derived from 3632

94 gamma irradiated $M 2$ lines and the resulting Ipa1-1 mutant is a single gene recessive non-lethal

95 mutation (Larson et al., 2000; Rutger et al., 2004). KBNT Ipa is from the tropical japonica sub-

96 population of Oryza sativa, which contains resistance to rice blast (Magnaportha grisea)

97 isolates IB-1, IB-49, IC-17, and IG-1 and has translucent grain. Zhe733 is a chalky, high yielding

98 indica variety that is resistant to straight head disorder, rice water weevil and some rice blast

99 races (IE1K and IB-33) (Lee et al., 2009; Liu et al., 2008; Yan et al., 2005). The KBNT Ipa x Zhe733

100 is a registered mapping population (Rutger and Tai, 2005) which has previously been used for

101 mapping water weevil resistance, disease resistance, and straighthead (Yan et al., 2005). It was

102 chosen for this study as there is a large difference in chalk concentration between the parents

103 (KBNT Ipa Is mean of $3.15 \%$ chalk and Zhe733 with an Is mean of $25.37 \%$ chalk) and because

104 both parents are long grain varieties and thus, grain shape is not a confounding factor (Wan et 105 al. 2005). Incorporating low phytic acid mutations into rice and other crops can be beneficial for

107 both health and environmental reasons. Phytic acid binds much of the available phosphorus in 108 seeds into an insoluble form that cannot be digested by humans and other monogastric 109 animals. In food products phytic acid has a two-fold negative effect on the environment. The 110 insoluble phosphorus is passed by humans and agricultural animals leading to high phosphorus 111 contents in sewage/waste and contributes to eutrophication of lakes, rivers and drinking water. 112 The resulting insoluble phosphorus in manure is unavailable to agricultural crops until it is 
113 broken down by soil microorganisms requiring the additional use of non-renewable inorganic

114 phosphorus fertilizers, which in turn compounds excess phosphorus run off into waterways

115 (Brinch-Pedersen et al., 2002). While a few health benefits have been attributed to phytic acid,

116 the negative aspects of phytic acid in the diet out-weigh the benefits (Raboy, 2009; Schlemmer

117 et al., 2009). Phytic acid is a strong chelator and can bind iron, zinc, calcium, magnesium and

118 manganese into insoluble salts in human and animal digestive systems also. This in turn

119 increases the risk of vitamin and micronutrient deficiencies, especially in developing countries

120 where dietary choices are limited (Raboy, 2007).

121 In seeds phytic acid, also known as myo-inositol-1,2,3,4,5,6-hexakisphosphate, serves as

122 the main storage form of phosphorus and may contain approximately $75 \%$ of the total

123 phosphorus in the seed (Raboy, 2009). Phytic acid forms salt complexes with many nutrients

124 that can later be released in the presence of phytases to provide nutrition to the developing

125 embryo during seed germination. The nearest known homolog to the rice Ipa1-1 is a 2-

126 phosphoglycerate kinase found in hyperthermophilic methanogens (Kim et al., 2008;

127 Lehmacher and Hensel, 1994). The exact mechanism by which the Ipa1-1 gene functions is

128 currently unknown. However, Raboy (2009) suggests that the protein encoded by Lpa1 may

129 function similarly to 2-phosphoglycerate kinase by creating an intermediate compound for

130 phytic acid synthesis as well as producing a second compound that protects phytic acid

131 intermediary compounds from degradation.

132 In the current study, our aims were to identify the QTL that control chalk within long

133 grain rice, and to determine the effect of the low phytic acid 1-1 allele on chalk (if any). This

134 population was genotyped and phenotyped for chalk and potential interacting agronomic traits, 
135 and QTL analysis was performed. The long term objectives are to understand the genetic and

136 biochemical components that cause chalk, and to obtain molecular markers to be used for

137 selection of low chalk grains in rice breeding.

138 


\section{Seed Source and growing conditions}

143 Stocks Oryza (GSOR) collection (https://www.ars.usda.gov/Main/docs.htm?docid=14200) that

144 had been produced in 2004 in Stuttgart, AR. The software MapPop V 1.0 (Vision et al., 2000)

145 and existing molecular data (Rutger and Tai, 2005) were used to select 202 diverse RIL's for

146 planting. To account for environmental variables, particularly differences in temperatures

147 during grainfill that affect chalk, seed was planted on two planting dates a month apart, April

$14815^{\text {th }} 2013$ and May $15^{\text {th }} 2013$, in Stuttgart, Arkansas. Three replications were used for each

149 planting date and plants were grown in a randomized complete-block design. F13 seed from

150 RIL's grown in 2013 was used for planting the following year. In 2014, the same experimental

151 design was used at the Stuttgart, Arkansas location with two planting dates (April $21^{\text {st }} 2014$ and

152 May $21^{\text {st } 2014) .}$

153 Seed was planted in single rows approximately $0.27 \mathrm{~m}^{2}$ with a Hege 1000 plot planter

154 (Wintersteiger Inc., Salt lake City, UT). The parents KBNT Ipa and Zhe733 were grown as checks

155 within each replication in the randomized complete-block design. The field was bordered by

156 two rows of rice to prevent edge effects. In both years, prior to planting $56 \mathrm{~kg}$ phosphorus ha ${ }^{-1}$,

$157101 \mathrm{~kg}$ potassium ha- ${ }^{-1}$, and $11 \mathrm{~kg}_{\mathrm{zinc} \mathrm{ha}}{ }^{-1}$ were applied according to soil test recommendations.

158 To reduce the possibility of lodging, only $56 \mathrm{~kg}$ nitrogen ha $^{-1}$ was applied just prior to

159 permanent flood. A pre-emergent herbicide was applied prior to planting and subsequent

160 treatments of herbicide or pesticide applications were used as necessary throughout the 
161 growing season. The lines were harvested individually as their seed reached maturity when the

162 full panicle appeared ripened and straw color, at $18-20 \%$ moisture.

164 Field and lab measurements

Heading Days (days to $50 \%$ heading from emergence), Days to Harvest, and Grainfill

166 (Harvest-Heading days) were determined for all plots. Hand-harvested plots were threshed

167 (Bill's Welding, Pullman, WA), the rice was dried to approximately $12 \%$ moisture with a forced

168 air drier at $28 \mathrm{C}$ and then stored at $4 \mathrm{C}$ and $50 \%$ relative humidity prior to further analysis. The

169 grain was aspirated (Air Blast Seed Cleaner, Almaco, Nevada, IA) and $100 \mathrm{~g}$ of rough rice was

170 sampled prior to milling. Following the 2013 field season, the rough rice was milled and broken

171 grains separated (PAZ-1 DTA, Zaccaria USA, Anna, TX) to determine percent total milled rice and

172 percent whole milled rice. Using samples of the original 2004 produced seed and that from the

1732013 and 2014 harvests, approximately 10g of rough rice were de-hulled to produce brown rice

174 (Satake Rice Machine, Satake Engineering Co., Ltd, Tokyo, Japan). Percent chalk and grain

175 dimensions were calculated using WinSEEDLE Pro V.2007E (Regents Instruments Inc., Canada)

176 and an Epson Perfection V700 photo scanner (Epson America Inc., Long Beach, CA) using

177 approximately 140 whole milled grain or brown rice kernels.

178 Temperature and weather data were collected (hourly) on site by the USDA-ARS

179 weather station (www.ars.usda.gov/Main/Docs.htm?docid=23563). We calculated the daily

180 averages for air temperature, night time air temperature (NTAT), relative humidity, and rainfall

181 over a 20 day grainfill period following heading for each plot. We considered those

182 temperatures that occur between the hours of 8PM and 6AM to be NTATs. Degree-day-10 
183 (DD10) thermal units over the course of each day were calculated according to methods used

184 by Ambardekar et al. (2011) and averaged across the 20 days following heading for each plot.

185 Frequencies of the NTATs during a 20 day interval following heading were used to calculate the

186 95th percentiles of NTAT frequency ( $\mathrm{NT}_{95}$ ) for each plot (Ambardekar et al., 2011). All weather

187 calculations were made using the $R$ statistical language ( $R$ Core Team, 2016).

188

Statistical analyses were performed using JMP ${ }^{\circledR} 12$ Software (SAS Institute Inc., 2015) to

189 assess the effects of weather on chalk and to calculate Least-Squares Means (LSmeans) of

190 percent chalk of each RIL to use in subsequent QTL analysis. Percent chalk was used as

191 response vector in a linear model. The RIL (genotype) was used as a fixed effect. Weather data

192 from within a 20 day interval after heading were also used as fixed effects including: average air

193 temperature, average NTAT, $\mathrm{NT}_{95}, \mathrm{DD} 10$, average relative humidity, and total rainfall. The

194 planting year and planting date were used as random effects. The mixed model partitions the

195 model into fixed and random effects. The year and planting date are restricted maximum

196 likelihood (REML) estimators that are free of fixed effects. Subsequently, to calculate LSmeans

197 of each RIL, percent chalk was again used as response vector in a linear model that included

198 only the significant fixed effects of the previous model (NT ${ }_{95}$, average NTAT, and average

199 relative humidity). LSmeans of percent chalk were also calculated for each RIL without the

200 weather related fixed effects for the purpose of comparison in the QTL analysis. Correlations

201 between traits were determined using the pairwise method (SAS Institute Inc, 2015).

202 Data from one hundred and sixteen SSR markers had been gathered on the KBNT Ipa $\mathrm{x}$

203 Zhe733 $F_{10}$ population during prior studies as described in Liu et al. (2008) and Lee et al. (2009).

204 RIL lines were advanced to the $F_{12}$ generation and 10 high polymorphic information content 
205 (PIC) value markers were used to verify that F12 lines were consistent with the molecular data

206 in the $F_{10}$ population and no out crossing had occurred. An additional 56 SSR markers and two

207 SNP markers were used on the $F_{12}$ RIL population. The markers used for this study and their

208 corresponding linkage map positions are shown in Supplemental Table 1. PCR conditions were

209 performed as described in Costanzo et al. (2011). An ABI Prism 3730 DNA analyzer was used to

210 identify the amplified fragments and data was analyzed using GeneMapper V 3.7 software (Life

211 Technologies Corp., 2004). One hundred and eighty five RIL's that had phenotypic data for both

212 years and genotype data consistent with F10 lines were selected for mapping.

213 Two SNP markers were designed for this study at or near the KBNT Ipa mutation using a

214 three primer SNP detection method similar to that described in Hayashi et al. (2004). In this

215 method a mismatch is made in the third base pair from the $3^{\prime}$ end of the forward primer and

216 the final base pair of the primer corresponds to the SNP. Two forward primers specific to their

217 corresponding SNP are used with a shared fluorophore labeled reverse primer. An additional

$2182 \mathrm{bp}$, matching the target sequence, is added on the $5^{\prime}$ end of one of the forward primers to

219 allow for a detectable size difference in the amplified product. The SNP ID2015477 is found on

220 chromosome two at $34.48 \mathrm{Mb}$ and was amplified with the forward primers

221 CTTGCTTGCGAAGTTGTGG (KBNT Ipa specific), TTGCTTGCTTGCGAAGTTGTGA (Zhe733 specific),

222 and a shared reverse primer ATAATACGAGCGGCGGAGC. The functional nucleotide

223 polymorphism responsible for the KBNT Ipa mutation is a C to T substitution and occurs on

224 chromosome 2 at $35.17 \mathrm{Mb}$. The KBNT Ipa specific forward primer is

225 AGCAAGAAGAAAGTCAGCCTTATA, wild type forward is CAAGAAGAAAGTCAGCCTTATG, and the 226 shared reverse is CAAGACCCAAACAACCATCG. 
A genetic linkage map was calculated using the Kosambi mapping function of MapDisto

228 V 1.7.5 Beta 4 (Lorieux, 2012). QTL analysis was performed using R/qtl (Broman et al., 2003).

229 Phenotypes and genotypes loaded with cross type set to "riself". Interval mapping and

230 composite interval mapping (CIM) were done using the commands "scanone" and "cim"

231 respectively using the "EM" algorithm. The logarithm (base 10) of odds (LOD) threshold was

232 determined using 1000 permutations. A QTL model was constructed using all loci exceeding

233 the LOD threshold. This model was used with the "addqtl" command to identify additional QTL

234 given the model. The "scantwo" command was used to perform a two-dimensional genome

235 scan with a two-QTL model. A QTL model was then built including all significant loci detected

236 by CIM, "addqtl", and the 2D QTL scan. The "addint" command was used to test for QTL

237 interactions. All significant interactions were then added to the QTL model. Drop-one-term

238 regression analysis was performed using "fitqtl" to select significant terms and interactions. The

239 "fitqtl" command was then used to calculate percent of variation explained and estimated

240 effects of each QTL and each QTL interaction term, and percent of the variance explained by

241 the full model.

243 RESULTS

244 The population of 187 individuals was genotyped with 174 SSR markers and 2 SNP

245 markers with 5.2 percent missing data (Supp. Table 1, Supp. Figure 1). The marker allele calls

246 were $44.9 \%$ homozygous for KBNT Ipa, $54.2 \%$ homozygous for Zhe733, and 0.9\% heterozygous.

247 The heterozygous loci were treated as missing data in the QTL analysis. The physical distance to 248 genetic map distance is approximately 0.2 to $0.3 \mathrm{cM}$ per megabase across entire chromosomes, 
249 but this is highly variable depending on the genomic region. Phenotypically, the RIL population

250 had a mean percent chalk (brown) of 18.69\% (12.16 SD), mean heading date (days to flowering)

251 of 77.09 days (8.48 SD), mean kernel length of $6.77 \mathrm{~mm}$ (0.55 SD), and mean kernel width of

$252 \quad 2.40 \mathrm{~mm}(0.24 \mathrm{SD})$.

253 Chalk measurements for 2013 were taken on both brown and milled white rice

254 harvested that year. There was concern that chalky grains would break up during milling

255 resulting in an under-estimate of percent grain chalk on the milled rice. However percent chalk

256 using milled rice was highly correlated with that of brown rice $(r=0.96, p<0.0001)$. In addition,

257 grain dimensions traits were highly correlated between the two; grain length, $r=0.92$, grain

258 width $r=0.90$, length:width $r=0.93, p<0.0001$ ). Moreover, a simple linear regression model

259 demonstrated that percent chalk in brown rice was an adequate predictor of percent chalk in

260 milled rice $\left(r^{2}=0.92\right)$ (Supp. Figure 2$)$. Thus, brown rice was deemed suitable for chalk and grain

261 dimension measurements and only brown rice measurements were determined for the 2014

262 growing season. Whole grain milling percent (percent head rice) was determined in the 2013

263 study and was not strongly correlated with any of the milled grain dimension traits $(r<0.2)$, but

264 was correlated with brown rice width $(r=-0.48, p<0.0001)$. Whole grain milling percent was

265 more strongly correlated with percent chalk in brown rice $(r=-0.56, p<0.0001)$ than with

266 percent chalk in milled rice $(r=-0.52, p<0.0001)$.

267 Chalk phenotypic data were collected over two years with two planting dates per year.

268 The RILs were considered fixed effects in the analysis of variance and accounted for $99 \%$ of the

269 variance in the model for percent grain chalk (data not shown). Of the remaining $1 \%$ variation

270 in the model, year explained 19\% whereas planting date explained $5 \%$ of the variation (Supp. 
271 Table 2). Thus, the wide distribution of the population for chalk was far greater than the

272 environmental effect (Figure 1).

273 Temperature is known to affect chalk development during grain filling (Ambardekar et

274 al. 2011, Lisle et al. 2000, Lanning et al. 2010, Counce et al., 2005). Thus, the effects of weather

275 were examined on a per-plot basis within a window of 20 days following heading, during grain

276 development. A significant effect was observed for NT95, average night temperature, and

277 average relative humidity (Table 1). However, average temperature, DD10, and total rainfall

278 were not significant. When only significant fixed effects were included in the model, increased

279 NT95 and average night temperature significantly increased the percent chalk $(p<0.0001)$ with a

280 lesser positive effect from average relative humidity $(p<0.037)$ (Table 2$)$. Unadjusted LSmeans

281 and LSmeans with adjustments for NT95, night temperature, and humidity were calculated for

282 each RIL and parent line for use in QTL mapping (Supp. Table 3). The RILs ranged from 2.43 to

$28352.61 \%$ chalk, whereas the parental means were 3.15\% for KBNT Ipa and $25.37 \%$ for Zhe 733.

284 The distribution of percent chalk LSmeans (adjusted for environmental predictors) in the RILS

285 indicates substantial transgressive variation for higher chalk with 51 out of 187 progeny (26.8\%)

286 exceeding the percent chalk of Zhe733, the higher chalk parent, while only two lines had lower

287 chalk than KBNT Ipa, the lower chalk parent (Figure 1). The two lines that were lower in LSmean

288 chalk were not significantly lower than KBNT Ipa.

289 Composite interval mapping, using combined data across both years and all planting

290 dates and adjusted for weather data, shows five distinct loci with LOD scores exceeding the

2910.05 threshold as determined by 1000 permutations (Figure 2, Table 3). Supp. Figure 3 shows

292 the QTL analysis done separately by year and by planting date. Supp. Figure 4 shows the QTL 
293 analysis done separately for weather adjusted and non-adjusted chalk. Similar patterns of QTL

294 peaks between adjusted and non-adjusted for weather and across planting dates and years

295 suggests that, although environmental factors influence the levels of chalk, the genetic loci that

296 affect chalk are consistent across environments (i.e., no gene $\mathrm{x}$ environment interaction).

297 Scanning for additional QTL in the context of the multiple QTL model revealed five

298 additional QTL with LOD > 1.5 (Table 4). A two dimensional QTL scan (scantwo) revealed the

299 same five additional QTL with evidence of conditional interactions (Supp. Table 4, Supp. Figure

300 5). Testing all possible interactions by adding one pairwise interaction at a time with the addint

301 procedure detected three significant interactions (Supp. Table 5), two of which were shared

302 interactions identified by scantwo. Table 5 shows the significance, percent of variation

303 explained, and estimated effects of all of the significant chalk QTL. All nine QTL and the two

304 QTL interactions in the model are significant $(p<0.031)$ and the full model explains $63.2 \%$ of the

305 variation for chalk (Supp. Table 6). At the preponderance of the loci, the Zhe 733 allele

306 increased chalkiness (indicated by positive estimated effect values), however at the qBCHK2

307 locus (2@148.0), the allele from Zhe 733 results in a 5.29\% decrease in chalk, possibly because

308 it associated with the wild-type (non-mutant form) of the phytic acid allele (Table 5).

309 Furthermore, although the parents differed in heading by $20 \mathrm{~d}$, there was no relationship of

310 days to heading and grain chalk nor was there any overlap in these QTL (Figure 6).

311 Positions of chalk loci in megabases (Mbp) are presented relative to positions of

312 previously reported QTLs and candidate genes in Figure 3 (Liu et al., 2011; Wan et al., 2005),

313 and relative to the QTL positions of other grain quality and agronomic traits measured in this

314 population in Supp. Figure 5. 


\section{DISCUSSION}

The RIL population derived from KBNT Ipa $x$ Zhe733 showed clear differences between

318 lines in percent chalk (Table 1, Sup. Table 3) indicating that chalk is largely controlled by

319 genetics. There was transgressive variation in percent chalk, but only in the direction of

320 increased chalk (greater than the higher chalk parent, Zhe 733). There were no lines with

321 significantly lower chalk than the low chalk KBNT Ipa parent. The transgressive variation

322 suggests that epistatis or additive effects at multiple recombined loci can act together to

323 substantially increase chalkiness. This may be a consequence of the inter-subspecific cross

324 between a tropical japonica (KBNT Ipa) and an indica (Zhe733) line. Because these results

325 suggest that the level of chalk in populations derived from wide crosses has the potential to be

326 very high in some lines, such populations would need to be screened for chalk when using such

327 material in breeding programs.

328 QTL for chalk were detected in the KBNT Ipa $\times$ Zhe733 RIL population that together

329 explain the majority (63.2\%) of the variation for the trait. Five significant QTL were found by

330 CIM (Table 3). Additionally, five smaller QTL that improve the predictive power of the model

331 were found by two-dimensional QTL and multiple-QTL model scans (Table 5). Out of the ten

332 QTL, the only loci where the Zhe733 allele reduced chalk were near the Ipa1-1 gene and on

333 chromosome 12 near marker RM270. The Ipa1-1 mutant allele could itself be a cause of

334 increased chalk and the non-mutant form of KBNT would not contain the allele that increases

335 chalk. If so, Zhe733 has little to offer in its potential to contribute alleles that would further

336 reduce chalk in an already low chalk tropical japonica line. This also helps to explain the

337 transgressive variation only occurring in the direction of higher chalk. Even though this 
338 mapping population was derived from two long grain cultivars, there was variation in grain

339 width of KBNT Ipa was $2.09 \mathrm{~mm}$ and Zhe 733 was $2.62 \mathrm{~mm}$ with the RILs having $2.40 \mathrm{~mm}$ (0.24

340 SD). Of the ten chalk QTL identified, four were associated with grain width or grain length:width

341 (Supp. Figure 6). Fitzgerald et al. (2009) have indicated that grain width is associated with grain

342 chalk. These results suggest that even small differences in grain width are related to chalk

343 development. Three of the other chalk QTL were co-located with total or whole grain milling

344 yields demonstrating the interrelationship of these traits.

345 QTL with marginally significant effects were supported by additional lines of evidence.

346 The QTL qBCHK5 co-locates (Figure 3) with a cloned gene that has a known chalky phenotype (Li

347 et al., 2014). The QTL qBCHK1-2 and qBCHK12 co-locate with Sar1a and Sar1b which have an

348 associated phenotype of floury shrunken seed and an increased level of glutelin precursor in

349 the endosperm (Tian et al., 2013). Five of the nine chalk QTL overlapped with previously

350 reported QTLs related to chalk (Figure 3).

351 The chalk QTL on chromosome 2 co-locates with the Ipa1-1 gene. The mutant Ipa1-1

352 may be causal or a closely linked gene has an allele from KBNT that has a large (increasing)

353 effect on percent chalk. To differentiate between the two possibilities, a new population could

354 be generated using the non-mutant KBNT line to be crossed with Zhe733. The exact

355 mechanisms by which low phytic acid may increase chalk are not known. Landoni et al. (2013)

356 reported the Ipa gene impacted lignin and protein content as well as the size and structure of

357 starch granules in maize. This suggests that Ipa in rice could impact how densely the starch

358 granules in the rice endosperm are packed and influence the appearance of chalk. Given the

359 importance of phosphorus in a multitude of enzymatic reactions and compounds that could 
360 contribute to chalk formation, it is reasonable that a gene responsible for regulating the

361 availability of inorganic phosphorus, such as Ipa1-1, could play a role in influencing chalk

362 formation. The KBNT Ipa line has the mutated Ipa allele that was associated with increased

363 chalk however it contains alleles for low chalk at nine additional QTL that additively explain the

364 low chalk phenotype of this line. The mutated KBNT-1-1 LPA allele is a unique allele that

365 occurred in a Kaybonnet genetic background that may be associated with an increase in chalk

366 relative to the non-mutant allele. However, currently there is no evidence that natural

367 variation in phytic acid levels occurring in other breeding lines are correlated with chalkiness.

368 Along with genetics, the environment, particularly the weather during the grain filling

369 stage, affects chalkiness. In this study we found that (in the two weeks following heading) the

370 night temperature and $\mathrm{NT}_{95}$ are positively correlated with percent chalk. This is in agreement

371 with previous reports (Ambardekar et al., 2011; Counce et al., 2005; Lanning et al., 2011; Li et

372 al., 2011). Average relative humidity was also positively correlated with chalk, although the

373 magnitude of the effect was weak (Table 2). Correcting for weather data during grain filling did

374 not substantially change the QTL that were detected or their relative LOD scores (Supp. Figure

375 4). This suggests that the loci will have a similar effect across environments and that the

376 markers are an effective selection tool.

377 To meet the challenge of breeding high yielding and high quality rice for a future with

378 potential climate change and limited resources, it will be important to understand the genetics

379 that govern grain quality traits such as chalk (Sreenivasulu et al., 2015). Warmer temperatures

380 increase chalk directly, and along with higher $\mathrm{CO}_{2}$ levels, may indirectly increase other biotic

381 and abiotic stresses that will exacerbate problems with chalk (Fitzgerald et al., 2009; Lyman et 
382 al., 2013). Limited water resources could necessitate changes in production methods or shifts in 383 growing regions that could impact chalk as well. The incorporation of new genetic diversity into 384 elite rice breeding lines through wide crosses could provide the needed variation to breed for 385 the adaptation to environmental or limited resource challenges. However use of new genetic 386 material has a strong potential of negatively impacting grain quality traits such as chalk. Also, 387 hybrids often rely on intra-subspecific variation for heterosis. Molecular markers for chalk 388 could help to eliminate alleles for high chalk in breeding programs through MAS and allow for 389 greater use of the full range of genetic diversity available in rice germplasm. 


\section{REFERENCES}

392 Ambardekar, A.A., Siebenmorgen, T.J., Counce, P.A., Lanning, S.B., Mauromoustakos, A., 2011. Impact of field-scale nighttime air temperatures during kernel development on rice milling quality. F. Crop. Res. 122, 179-185. doi:10.1016/j.fcr.2011.03.012

Ashida, K., Iida, S., Yasui, T., 2009. Morphological, physical, and chemical properties of grain and flour from chalky rice mutants. Cereal Chem. 86, 225-231.

Brinch-Pedersen, H., Sørensen, L.D., Holm, P.B., 2002. Engineering crop plants: Getting a handle on phosphate. Trends Plant Sci. 7, 118-125. doi:10.1016/S1360-1385(01)02222-1

Broman, K.W., Wu, H., Sen, Ś., Churchill, G.A., 2003. R/qtl: QTL mapping in experimental crosses. Bioinformatics 19, 889-890. doi:10.1093/bioinformatics/btg112

Childs, N., 2016. Rice Yearbook 2016 [WWW Document]. USDA ERS. URL http://www.ers.usda.gov/data-products/rice-yearbook.aspx

Chun, A., Song, J., Kim, K.-J., Lee, H.-J., 2009. Quality of head and chalky rice and deterioration of eating quality by chalky rice. J. Crop Sci. Biotech 12, 239-244.

Counce, P.A., Bryant, R.J., Bergman, C.J., Bautista, R.C., Wang, Y., Siebenmorgen, T.J., doi:10.1007/s12892-009-0142-4 developing and mature rice kernel. Cereal Chem. 45, 225-235.

411 Fitzgerald, M.A., McCouch, S.R., Hall, R.D., 2009. Not just a grain of rice: the quest for quality. 
413 Fujita, N., Yoshida, M., Kondo, T., Saito, K., Utsumi, Y., Tokunaga, T., Nishi, A., Satoh, H., 414 Park, J.H., Jane, J.L., Miyao, A., Hirochika, H., Nakamura, Y., 2007. Characterization of 415 SSIIIa-deficient mutants of rice: the function of SSIIIa and pleiotropic effects by SSIIIa 416 deficiency in the rice endosperm. Plant Physiol 144, 2009-2023.

417 doi:10.1104/pp.107.102533

418 Hayashi, K., Hashimoto, N., Daigen, M., Ashikawa, I., 2004. Development of PCR-based SNP 419 markers for rice blast resistance genes at the Piz locus. Theor. Appl. Genet. 108, 1212420 1220. doi:10.1007/s00122-003-1553-0

421 Kang, H.G., Park, S., Matsuoka, M., An, G., 2005. White-core endosperm floury endosperm-4 in 422 rice is generated by knockout mutations in the C4-type pyruvate orthophosphate dikinase 423 gene (OsPPDKB). Plant J. 42, 901-911. doi:10.1111/j.1365-313X.2005.02423.x

424 Kepiro, J.L., McClung, A.M., Chen, M.H., Yeater, K.M., Fjellstrom, R.G., 2008. Mapping QTLs 425 for milling yield and grain characteristics in a tropical japonica long grain cross. J. Cereal $426 \quad$ Sci. 48, 477-485. doi:10.1016/j.jcs.2007.12.001

427 Khush, G.S., Paule, C.M., dela Cruz, N.M., 1979. Rice grain quality evaluation and improvement 428 at IRRI, in: In: Proceedings of Workshop in Chemical Aspects of Rice Grain Quality. Int. 429 Rice Res. Inst., Los Baños, Laguna, Philippines. International Rice Research Institute, Los 430 Baños, Laguna, Philippines, p. 22-31.

431 Kim, S.I., Andaya, C.B., Goyal, S.S., Tai, T.H., 2008. The rice OsLpa1 gene encodes a novel 432 protein involved in phytic acid metabolism. Theor. Appl. Genet. 117, 769-779. 
434 Landoni, M., Cerino Badone, F., Haman, N., Schiraldi, A., Fessas, D., Cesari, V., Toschi, I., 435 Cremona, R., Delogu, C., Villa, D., Cassani, E., Pilu, R., 2013. Low phytic acid 1 mutation 436 in maize modifies density, starch properties, cations, and fiber contents in the seed. J. Agric. 437 Food Chem. 61, 4622-4630. doi:10.1021/jf400259h

438 Lanning, S.B., Siebenmorgen, T.J., Counce, P.A., Ambardekar, A.A., Mauromoustakos, A., 439 2011. Extreme nighttime air temperatures in 2010 impact rice chalkiness and milling 440 quality. F. Crop. Res. 124, 132-136. doi:10.1016/j.fcr.2011.06.012

441 Larson, S.R., Rutger, J.N., Young, K.A., Raboy, V., 2000. Isolation and Genetic Mapping of a 442 Non-Lethal Rice (Oryza sativa L.) low phytic acid 1 Mutation. Crop Sci. 40, 1397-1405. 443 doi:10.2135/cropsci2000.4051397x

444 Lee, S., Wamishe, Y.A., Jia, Y., Liu, G., Jia, M.H., 2009. Identification of two major resistance 445 genes against race IE-1k of Magnaporthe oryzae in the indica rice cultivar Zhe733. Mol. $446 \quad$ Breed. 24, 127-134. doi:10.1007/s11032-009-9276-9

447 Lehmacher, A., Hensel, R., 1994. Cloning, sequencing and expression of the gene encoding 2448 phosphoglycerate kinase from methanothermus-fervidus. Mol. Gen. Genet. 242, 163-168.

449 Li, H., Chen, Z., Hu, M., Wang, Z., Hua, H., Yin, C., Zeng, H., 2011. Different effects of night $450 \quad$ versus day high temperature on rice quality and accumulation profiling of rice grain 451 proteins during grain filling. Plant Cell Rep. 30, 1641-1659. doi:10.1007/s00299-011-1074$452 \quad 2$

453 Li, Y., Fan, C., Xing, Y., Yun, P., Luo, L., Yan, B., Peng, B., Xie, W., Wang, G., Li, X., Xiao, J., 

Xu, C., He, Y., 2014. Chalk5 encodes a vacuolar H(+)-translocating pyrophosphatase influencing grain chalkiness in rice. Nat. Genet. 46, 398-404. doi:10.1038/ng.2923

456

457

458

459

460

461

462

463

464

465

466

467

468

469

470

471

472

473

474

Life Technologies Corp., 2004. GeneMapper, Version 3.7.

Lisle, A.J., Martin, M., Fitzgerald, M.A., 2000. Chalky and translucent rice grains differ in starch composition and structure and cooking properties. Cereal Chem. 77, 627-632. doi:10.1094/CCHEM.2000.77.5.627

Liu, G., Bernhardt, J.L., Jia, M.H., Wamishe, Y.A., Jia, Y., 2008. Molecular characterization of the recombinant inbred line population derived from a japonica-indica rice cross. Euphytica 159, 73-82. doi:10.1007/s10681-007-9459-6

Liu, X., Wan, X., Ma, X., Wan, J., 2011. Dissecting the genetic basis for the effect of rice chalkiness, amylose content, protein content, and rapid viscosity analyzer profile characteristics on the eating quality of cooked rice using the chromosome segment substitution line population across ei. Genome 54, 64-80. doi:10.1139/G10-070

Lorieux, M., 2012. MapDisto: Fast and efficient computation of genetic linkage maps. Mol. Breed. 30, 1231-1235. doi:10.1007/s11032-012-9706-y

Lyman, N.B., Jagadish, K.S. V, Nalley, L.L., Dixon, B.L., Siebenmorgen, T., 2013. Neglecting rice milling yield and quality underestimates economic losses from high-temperature stress. PLoS One 8. doi:10.1371/journal.pone.0072157

Patindol, J., Wang, Y.J., 2003. Fine structures and physicochemical properties of starches from chalky and translucent rice kernels. J. Agric. Food Chem. 51, 2777-2784. doi:10.1021/jf026101t 
475 Peng, C., Wang, Y., Liu, F., Ren, Y., Zhou, K., Lv, J., Zheng, M., Zhao, S., Zhang, L., Wang, C.,

476 Jiang, L., Zhang, X., Guo, X., Bao, Y., Wan, J., 2014. FLOURY ENDOSPERM6 encodes a

477 CBM48 domain-containing protein involved in compound granule formation and starch

478 synthesis in rice endosperm. Plant J. 77, 917-930. doi:10.1111/tpj.12444

479 Raboy, V., 2009. Approaches and challenges to engineering seed phytate and total phosphorus.

480 Plant Sci. 177, 281-296. doi:10.1016/j.plantsci.2009.06.012

481 Raboy, V., 2007. The ABCs of low-phytate crops. Nat. Biotechnol. 25, 874-875.

482 doi:10.1038/nbt0807-874

483 R Core Team, 2016. R: A language and environment for statistical computing.

484 Rutger, J.N., Raboy, V., Moldenhauer, K.A.K., Bryant, R.J., Lee, F.M., Gibbons, J., 2004.

485 Registration of KBNT 1pa1-1 Low Phytic Acid Germplasm of Rice. Crop Sci. 44, 363.

486 Rutger, J.N., Tai, T.H., 2005. Registration of K/Z mapping population of rice. Crop Sci. 45, $487 \quad 2671-2672$.

488 SAS Institute Inc., 2015. JMP®, Version 12.

489 Schlemmer, U., Frølich, W., Prieto, R.M., Grases, F., 2009. Phytate in foods and significance for 490 humans: Food sources, intake, processing, bioavailability, protective role and analysis. Mol. $491 \quad$ Nutr. Food Res. 53, 330-375. doi:10.1002/mnfr.200900099

492 Sreenivasulu, N., Butardo, V.M., Misra, G., Cuevas, R.P., Anacleto, R., Kishor, P.B.K., 2015.

493 Designing climate-resilient rice with ideal grain quality suited for high-temperature stress. J. 494 Exp. Bot. 66, 1737-1748. doi:10.1093/jxb/eru544 
Tian, L., Dai, L.L., Yin, Z.J., Fukuda, M., Kumamaru, T., Dong, X.B., Xu, X.P., Qu, L.Q., 2013. Small GTPase Sar1 is crucial for proglutelin and $\alpha$-globulin export from the endoplasmic reticulum in rice endosperm. J. Exp. Bot. 64, 2831-2845. doi:10.1093/jxb/ert128

Vision, T.J., Brown, D.G., Shmoys, D.B., Durrett, R.T., Tanksley, S.D., 2000. Selective mapping: A strategy for optimizing the construction of high- density linkage maps. Genetics $155,407-420$.

Wan, X.Y., Wan, J.M., Weng, J.F., Jiang, L., Bi, J.C., Wang, C.M., Zhai, H.Q., 2005. Stability of QTLs for rice grain dimension and endosperm chalkiness characteristics across eight environments. Theor. Appl. Genet. 110, 1334-1346. doi:10.1007/s00122-005-1976-x

Wang, E., Wang, J., Zhu, X., Hao, W., Wang, L., Li, Q., Zhang, L., He, W., Lu, B., Lin, H., Ma, H., Zhang, G., He, Z., 2008. Control of rice grain-filling and yield by a gene with a potential signature of domestication. Nat. Genet. 40, 1370-4. doi:10.1038/ng.220

Woo, M.O., Ham, T.H., Ji, H.S., Choi, M.S., Jiang, W., Chu, S.H., Piao, R., Chin, J.H., Kim, J.A., Park, B.S., Seo, H.S., Jwa, N.S., McCouch, S.R., Koh, H.J., 2008. Inactivation of the UGPase1 gene causes genic male sterility and endosperm chalkiness in rice (Oryza sativa L.). Plant J. 54, 190-204. doi:10.1111/j.1365-313X.2008.03405.x

Yamakawa, H., Hirose, T., Kuroda, M., Yamaguchi, T., 2007. Comprehensive expression profiling of rice grain filling-related genes under high temperature using DNA microarray. Plant Physiol. 144, 258-277.

Yan, W., Dilday, R.H., Tai, T.H., Gibbons, J.W., McNew, R.W., Rutger, J.N., 2005. Differential response of rice germplasm to straighthead induced by arsenic. Crop Sci. 45, 1223-1228. 
516 doi:10.2135/cropsci2004.0348

517

518 


\section{$519 \quad$ Figure legends}

520

521

522

523 environmental predictors) in the KBNT Ipa $\times$ Zhe733 RILs.

525 Figure 2. Composite interval mapping (solid line) and standard interval mapping (dotted line)

526 for chalk QTL. Significant LOD thresholds (at $p<0.05$ ) based on 1000 permutations are shown

527 as a horizontal line of the style corresponding to the mapping method.

528

529 Figure 3. Chromosome map showing positions (in Mbp) of chalk QTL found in the current study

530 (labeled with prefix qBCHK), previously reported chalk QTL and candidate genes. QTL where the

531 TeQing parent allele reduced chalk are blue and those that increased chalk are red.

532

533 


\section{Figure 1.}

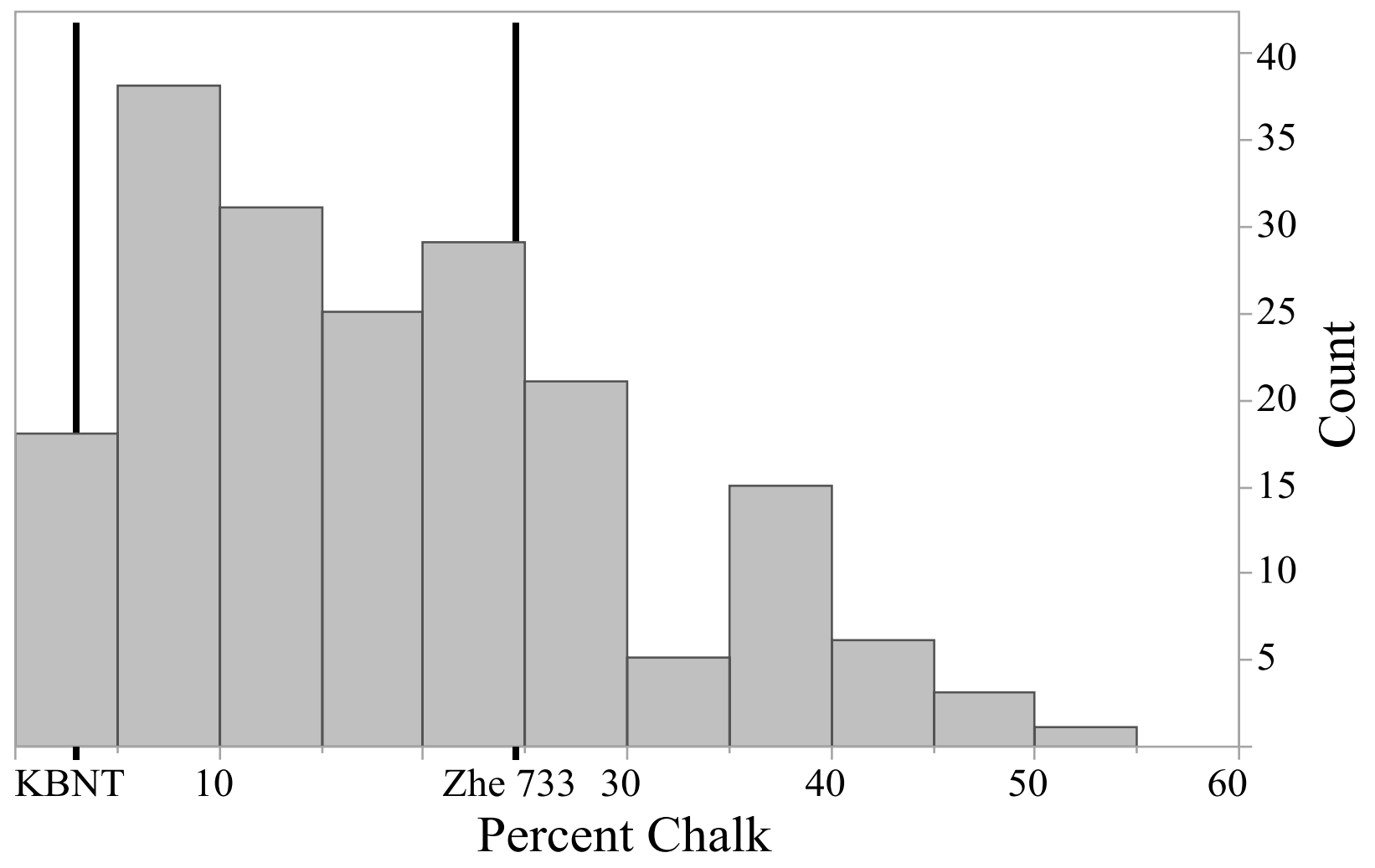




\section{Figure 3.}

Chr. 1

Chr. 2

Chr. 4

Chr. 5

Chr. 9

Chr. 11 Chr. 12
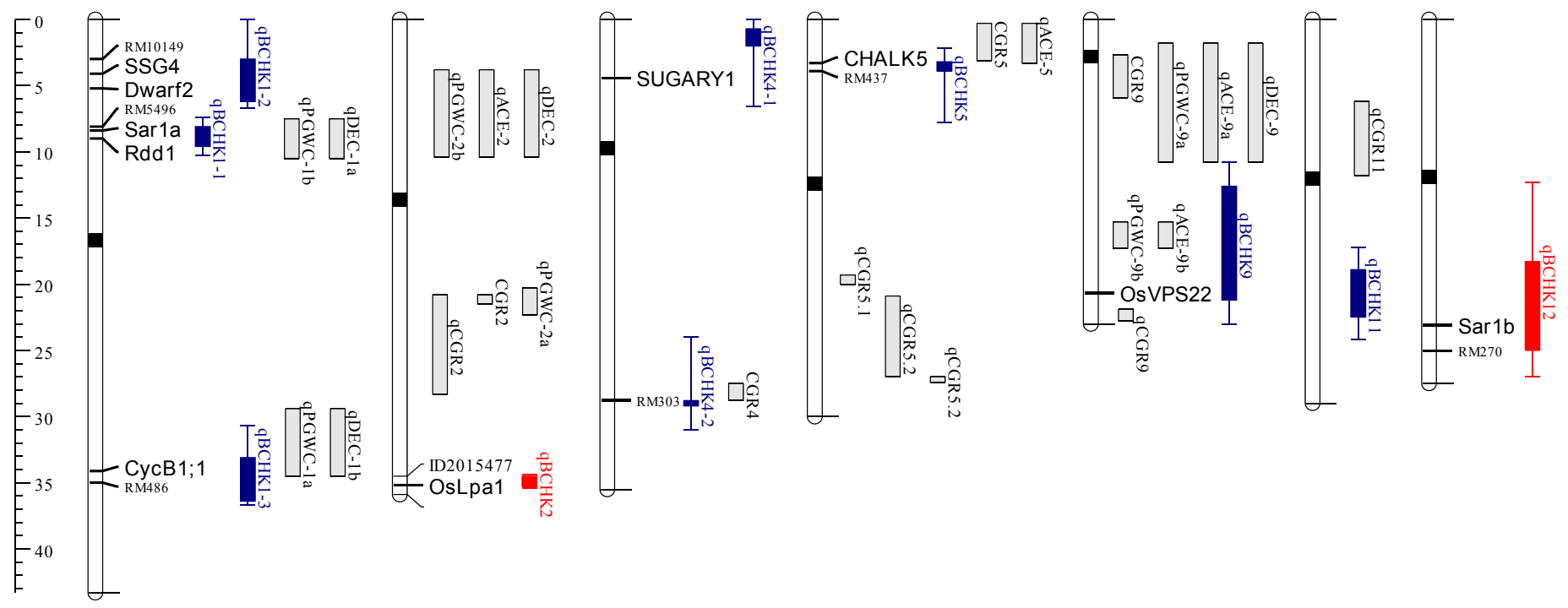
Table 1. Linear model fixed effect tests for genotype and environmental predictors of chalk.

\begin{tabular}{lrr}
\hline Effect & F Ratio & Prob $>$ F \\
\hline Line & 145.51 & $<.0001$ \\
NT95 & 42.18 & $<.0001$ \\
Avg. night temp. C & 19.48 & $<.0001$ \\
Avg. temp. C & 0.64 & 0.424 \\
DD10 & 0.85 & 0.357 \\
Avg. rel. humidity & 27.67 & $<.0001$ \\
Total rainfall cm & 0.67 & 0.414 \\
\hline
\end{tabular}

Table 2. Linear model parameter estimates for significant fixed effects for environmental predictors of chalk.

\begin{tabular}{lrrrr}
\hline Effect & Estimate & Std Error & $\mathrm{t}$ Ratio & Prob $>|\mathrm{t}|$ \\
\hline NT95 & 1.034 & 0.193 & 5.36 & $<.0001$ \\
Avg. night temp. C & 1.356 & 0.206 & 6.58 & $<.0001$ \\
Avg. rel. humidity & 0.090 & 0.043 & 2.09 & 0.0367 \\
\hline
\end{tabular}

Table 3. Nearest markers to significant $(\mathrm{p}<0.05)$ chalk QTL peaks and estimated cM positions.

\begin{tabular}{lrrrr}
\hline Nearest & & & & \\
Marker & Chr. & cM & LOD & P-value \\
\hline RM5496 & 1 & 31.42 & 7.17 & 0.001 \\
RM486 & 1 & 106.42 & 5.47 & 0.005 \\
ID2015477 & 2 & 148.00 & 14.65 & 0.001 \\
RM335 & 4 & 2.72 & 5.29 & 0.005 \\
RM303 & 4 & 104.00 & 3.97 & 0.048 \\
\hline
\end{tabular}

Table 4. Additional chalk QTL with LOD > 1.5 in the context of a multiple QTL model (addqtl).

\begin{tabular}{lrrr}
\hline Nearest & & & \\
Marker & Chr. & cM & LOD \\
\hline RM10149 & 1 & 1.42 & 1.88 \\
RM437 & 5 & 32 & 2.13 \\
RM105 & 9 & 33 & 2.78 \\
RM229 & 11 & 69 & 2.92 \\
RM270 & 12 & 68 & 1.54 \\
\hline
\end{tabular}


Table 5. Estimated effects of all significant chalk QTL and pairs of QTL in the model. The effect is the change in phenotype conferred by the Zhe733 allele.

\begin{tabular}{|c|c|c|c|c|c|c|c|c|c|}
\hline \multirow{2}{*}{ QTL } & \multicolumn{3}{|c|}{ Type } & \multicolumn{3}{|c|}{$\mathrm{F}$} & \multicolumn{3}{|l|}{ Est. } \\
\hline & df & III SS & LOD & \%var & value & Pvalue (F) & effect & SE & $\mathrm{t}$ \\
\hline $1 @ 1.4$ & 1 & 434 & 1.84 & 1.70 & 8.06 & 0.005 & 1.78 & 0.63 & 2.82 \\
\hline $1 @ 31.4$ & 3 & 2205.6 & 8.59 & 8.65 & 13.66 & $4.82 \mathrm{E}-08$ & 2.37 & 0.73 & 3.27 \\
\hline $1 @ 106.4$ & 1 & 1516.7 & 6.09 & 5.95 & 28.18 & 3.34E-07 & 2.82 & 0.57 & 4.91 \\
\hline $2 @ 148.0$ & 2 & 6661.8 & 21.82 & 26.13 & 61.89 & $<2 \mathrm{E}-016$ & -5.29 & 0.58 & -9.18 \\
\hline 4@2.0 & 2 & 1866.9 & 7.38 & 7.32 & 17.34 & $1.35 \mathrm{E}-07$ & 2.80 & 0.57 & 4.91 \\
\hline $4 @ 104.0$ & 1 & 1115.4 & 4.57 & 4.37 & 20.73 & $9.3 \mathrm{E}-06$ & 2.60 & 0.59 & 4.41 \\
\hline $5 @ 32.0$ & 1 & 277.6 & 1.19 & 1.09 & 5.16 & 0.024 & 1.43 & 0.61 & 2.34 \\
\hline 9@33.0 & 1 & 528.7 & 2.23 & 2.07 & 9.82 & 0.002 & 1.34 & 0.59 & 2.27 \\
\hline $11 @ 69.0$ & 1 & 362.1 & 1.54 & 1.42 & 6.73 & 0.010 & 1.84 & 0.59 & 3.13 \\
\hline $12 @ 68.0$ & 1 & 411.3 & 1.75 & 1.61 & 7.64 & 0.006 & -1.67 & 0.63 & -2.65 \\
\hline 1@31.4:2@148.0 & 1 & 432.3 & 1.83 & 1.70 & 8.03 & 0.005 & -1.57 & 0.59 & -2.67 \\
\hline 1@31.4:4@2.0 & 1 & 255.6 & 1.09 & 1.00 & 4.75 & 0.031 & 0.83 & 0.58 & 1.43 \\
\hline Intercept & & & & & & & 17.79 & 0.62 & 28.76 \\
\hline
\end{tabular}

Supplementary Table 1. Markers used for genotyping the Kbnt lpa x Zhe733 RIL population including primer sequences, MSU7 pseudomolecule assembly coordinates, and estimated genetic map positions.

[See attachment]

Supplementary Table 2. REML variance component estimates for random effects of year and planting date.

\begin{tabular}{llrlllr}
\hline Random & Var & Var & Std & $95 \%$ & $95 \%$ & Percent \\
Effect & Ratio & Component & Error & \multicolumn{1}{l}{ Lower } & \multicolumn{1}{l}{ Upper } & of Total \\
\hline Year & 0.251 & 2.817 & 4.581 & -6.161 & 11.794 & 19.032 \\
Planting & 0.066 & 0.746 & 0.771 & -0.765 & 2.257 & 5.04 \\
Residual & & 11.237 & 0.348 & 10.585 & 11.951 & 75.93 \\
\hline Total & & 14.799 & 4.596 & 8.734 & 30.387 & 100 \\
\hline
\end{tabular}


Supplementary Table 3. LSmeans of each line for chalk and chalk adjusted for weather with RILs sorted from low to high percent chalk.

\begin{tabular}{|c|c|c|c|c|}
\hline Line & $\begin{array}{l}\text { Least } \\
\text { Sq } \\
\text { Mean } \\
\end{array}$ & $\begin{array}{l}\text { Std } \\
\text { Error }\end{array}$ & $\begin{array}{l}\text { Adjusted } \\
\text { Least Sq } \\
\text { Mean }\end{array}$ & $\begin{array}{l}\text { Adjusted } \\
\text { Std } \\
\text { Error } \\
\end{array}$ \\
\hline GSOR100171 & 2.43 & 1.97 & 2.35 & 1.59 \\
\hline GSOR100137 & 2.49 & 1.97 & 2.48 & 1.59 \\
\hline GSOR100099 & 3.30 & 1.97 & 3.24 & 1.59 \\
\hline GSOR100083 & 3.32 & 1.97 & 3.38 & 1.59 \\
\hline GSOR100043 & 3.42 & 1.97 & 3.73 & 1.59 \\
\hline GSOR100169 & 3.48 & 1.97 & 3.37 & 1.59 \\
\hline GSOR100341 & 3.74 & 1.97 & 3.16 & 1.59 \\
\hline GSOR100298 & 3.76 & 1.97 & 3.61 & 1.59 \\
\hline GSOR100295 & 3.97 & 1.97 & 4.11 & 1.59 \\
\hline GSOR100329 & 4.16 & 1.97 & 3.79 & 1.59 \\
\hline GSOR100241 & 4.17 & 1.97 & 4.42 & 1.59 \\
\hline GSOR100159 & 4.29 & 1.97 & 4.04 & 1.59 \\
\hline GSOR100069 & 4.46 & 1.97 & 4.50 & 1.59 \\
\hline GSOR100317 & 4.65 & 1.97 & 3.96 & 1.59 \\
\hline GSOR100032 & 4.73 & 1.97 & 4.06 & 1.59 \\
\hline GSOR100067 & 4.93 & 1.97 & 5.07 & 1.59 \\
\hline GSOR100085 & 5.00 & 1.97 & 4.44 & 1.59 \\
\hline GSOR100237 & 5.01 & 1.97 & 5.14 & 1.59 \\
\hline GSOR100092 & 5.40 & 1.97 & 5.48 & 1.59 \\
\hline GSOR100312 & 5.40 & 1.99 & 6.01 & 1.62 \\
\hline GSOR100059 & 5.49 & 1.97 & 4.82 & 1.59 \\
\hline GSOR100168 & 5.80 & 1.97 & 6.26 & 1.59 \\
\hline GSOR100068 & 5.83 & 1.97 & 6.05 & 1.59 \\
\hline GSOR100337 & 5.86 & 1.97 & 5.81 & 1.59 \\
\hline GSOR100319 & 6.14 & 1.97 & 6.34 & 1.59 \\
\hline GSOR100030 & 6.19 & 1.97 & 5.98 & 1.59 \\
\hline GSOR100270 & 6.28 & 1.97 & 6.17 & 1.59 \\
\hline GSOR100154 & 6.48 & 1.97 & 5.95 & 1.59 \\
\hline GSOR100140 & 6.50 & 1.99 & 6.82 & 1.62 \\
\hline GSOR100231 & 6.84 & 1.97 & 6.96 & 1.59 \\
\hline GSOR100273 & 6.85 & 1.97 & 6.81 & 1.59 \\
\hline GSOR100123 & 6.94 & 3.88 & 7.80 & 3.58 \\
\hline GSOR100324 & 6.94 & 1.97 & 6.78 & 1.59 \\
\hline GSOR100118 & 6.97 & 1.99 & 6.75 & 1.62 \\
\hline GSOR100125 & 6.97 & 1.99 & 6.82 & 1.62 \\
\hline
\end{tabular}




$\begin{array}{lrrrr}\text { GSOR100094 } & 7.21 & 1.97 & 7.56 & 1.59 \\ \text { GSOR100251 } & 7.24 & 1.97 & 7.29 & 1.59 \\ \text { GSOR100242 } & 7.27 & 1.97 & 7.51 & 1.59 \\ \text { GSOR100039 } & 7.28 & 1.97 & 7.44 & 1.59 \\ \text { GSOR100147 } & 7.39 & 1.97 & 7.55 & 1.59 \\ \text { GSOR100185 } & 7.51 & 1.97 & 7.00 & 1.59 \\ \text { GSOR100208 } & 7.53 & 1.97 & 7.09 & 1.59 \\ \text { GSOR100248 } & 7.87 & 1.97 & 7.40 & 1.59 \\ \text { GSOR100274 } & 8.05 & 1.97 & 7.41 & 1.59 \\ \text { GSOR100234 } & 8.27 & 1.97 & 8.37 & 1.59 \\ \text { GSOR100139 } & 8.34 & 1.97 & 8.44 & 1.59 \\ \text { GSOR100347 } & 8.47 & 1.99 & 8.96 & 1.62 \\ \text { GSOR100041 } & 8.94 & 1.97 & 9.16 & 1.59 \\ \text { GSOR100296 } & 9.12 & 1.97 & 8.55 & 1.59 \\ \text { GSOR100316 } & 9.27 & 1.97 & 10.34 & 1.59 \\ \text { GSOR100290 } & 9.38 & 1.97 & 9.30 & 1.59 \\ \text { GSOR100115 } & 9.48 & 1.97 & 9.26 & 1.59 \\ \text { GSOR100267 } & 9.53 & 1.97 & 10.04 & 1.59 \\ \text { GSOR100283 } & 9.61 & 1.97 & 9.54 & 1.59 \\ \text { GSOR100038 } & 9.67 & 1.97 & 9.87 & 1.59 \\ \text { GSOR100177 } & 9.82 & 1.97 & 9.97 & 1.59 \\ \text { GSOR100082 } & 9.87 & 1.97 & 9.62 & 1.59 \\ \text { GSOR100145 } & 10.06 & 1.97 & 10.20 & 1.59 \\ \text { GSOR100093 } & 10.64 & 1.97 & 10.72 & 1.59 \\ \text { GSOR100074 } & 10.84 & 1.97 & 10.74 & 1.59 \\ \text { GSOR100116 } & 11.15 & 1.97 & 11.95 & 1.59 \\ \text { GSOR100284 } & 11.35 & 1.97 & 11.61 & 1.59 \\ \text { GSOR100339 } & 11.41 & 1.97 & 12.21 & 1.59 \\ \text { GSOR100353 } & 11.79 & 1.97 & 12.61 & 1.59 \\ \text { GSOR100042 } & 12.25 & 1.97 & 12.15 & 1.59 \\ \text { GSOR100176 } & 12.28 & 1.97 & 12.26 & 1.59 \\ \text { GSOR100089 } & 12.50 & 1.97 & 12.37 & 1.59 \\ \text { GSOR100344 } & 12.72 & 1.97 & 12.92 & 1.59 \\ \text { GSOR100048 } & 12.76 & 1.97 & 12.33 & 1.59 \\ \text { GSOR100007 } & 12.85 & 1.97 & 12.64 & 1.59 \\ \text { GSOR100167 } & 12.97 & 1.97 & 12.81 & 1.59 \\ \text { GSOR100180 } & 13.17 & 1.97 & 13.91 & 1.59 \\ \text { GSOR100111 } & 13.35 & 1.97 & 13.97 & 1.59 \\ \text { GSOR100299 } & 13.47 & 1.97 & 13.54 & 1.59 \\ \text { GSOR100128 } & 13.62 & 1.97 & 13.62 & 1.59 \\ \text { GSOR100330 } & 13.74 & 1.97 & 13.45 & 1.59\end{array}$




$\begin{array}{lllll}\text { GSOR100292 } & 13.97 & 1.97 & 13.72 & 1.59 \\ \text { GSOR100120 } & 13.98 & 1.97 & 14.05 & 1.59 \\ \text { GSOR100260 } & 14.05 & 1.97 & 14.06 & 1.59 \\ \text { GSOR100309 } & 14.15 & 1.97 & 15.02 & 1.59 \\ \text { GSOR100285 } & 14.30 & 1.97 & 14.20 & 1.59 \\ \text { GSOR100306 } & 14.33 & 1.97 & 13.73 & 1.59 \\ \text { GSOR100025 } & 14.36 & 1.97 & 14.07 & 1.59 \\ \text { GSOR100304 } & 14.55 & 1.97 & 14.63 & 1.59 \\ \text { GSOR100301 } & 14.68 & 1.97 & 15.04 & 1.59 \\ \text { GSOR100152 } & 14.76 & 1.97 & 14.81 & 1.59 \\ \text { GSOR100340 } & 14.77 & 1.97 & 15.02 & 1.59 \\ \text { GSOR100143 } & 14.83 & 1.97 & 15.10 & 1.59 \\ \text { GSOR100350 } & 15.16 & 1.97 & 15.32 & 1.59 \\ \text { GSOR100117 } & 15.46 & 1.97 & 14.75 & 1.59 \\ \text { GSOR100227 } & 15.49 & 1.97 & 14.97 & 1.59 \\ \text { GSOR100333 } & 15.52 & 1.97 & 15.21 & 1.59 \\ \text { GSOR100293 } & 15.57 & 1.97 & 15.92 & 1.59 \\ \text { GSOR100294 } & 16.05 & 1.97 & 15.95 & 1.60 \\ \text { GSOR100050 } & 16.21 & 1.97 & 16.68 & 1.59 \\ \text { GSOR100228 } & 16.28 & 1.97 & 16.31 & 1.59 \\ \text { GSOR100017 } & 16.42 & 1.97 & 15.73 & 1.59 \\ \text { GSOR100282 } & 16.47 & 1.97 & 16.43 & 1.59 \\ \text { GSOR100210 } & 16.87 & 1.97 & 16.90 & 1.59 \\ \text { GSOR100012 } & 16.91 & 1.97 & 16.70 & 1.59 \\ \text { GSOR100277 } & 17.05 & 1.97 & 16.74 & 1.59 \\ \text { GSOR100151 } & 17.09 & 1.97 & 17.29 & 1.59 \\ \text { GSOR100160 } & 17.38 & 1.97 & 16.62 & 1.59 \\ \text { GSOR100031 } & 17.43 & 1.97 & 17.59 & 1.59 \\ \text { GSOR100003 } & 17.93 & 1.97 & 17.74 & 1.59 \\ \text { GSOR100320 } & 18.16 & 1.97 & 17.99 & 1.59 \\ \text { GSOR100252 } & 18.48 & 1.97 & 18.27 & 1.59 \\ \text { GSOR100336 } & 18.57 & 1.97 & 18.55 & 1.59 \\ \text { GSOR100289 } & 19.07 & 1.99 & 19.14 & 1.62 \\ \text { GSOR100193 } & 19.12 & 1.97 & 19.33 & 1.59 \\ \text { GSOR100044 } & 20.36 & 1.97 & 19.98 & 1.59 \\ \text { GSOR100129 } & 20.56 & 1.97 & 20.87 & 1.59 \\ \text { GSOR100146 } & 20.88 & 1.97 & 21.51 & 1.59 \\ \text { GSOR100195 } & 21.11 & 1.97 & 21.02 & 1.59 \\ \text { GSOR100264 } & 21.21 & 1.97 & 21.02 & 1.59 \\ \text { GSOR100352 } & 21.34 & 1.97 & 20.58 & 1.59 \\ \text { GSOR100066 } & 21.38 & 1.97 & 21.25 & 1.59\end{array}$




$\begin{array}{lllll}\text { GSOR100063 } & 21.62 & 1.97 & 21.73 & 1.59 \\ \text { GSOR100351 } & 21.76 & 1.97 & 22.78 & 1.59 \\ \text { GSOR100016 } & 21.92 & 1.97 & 21.83 & 1.59 \\ \text { GSOR100105 } & 22.25 & 1.97 & 22.22 & 1.59 \\ \text { GSOR100191 } & 22.47 & 1.97 & 22.71 & 1.59 \\ \text { GSOR100008 } & 22.57 & 1.97 & 22.18 & 1.59 \\ \text { GSOR100109 } & 22.79 & 1.97 & 22.64 & 1.59 \\ \text { GSOR100057 } & 23.02 & 1.97 & 23.50 & 1.59 \\ \text { GSOR100342 } & 23.02 & 1.97 & 23.01 & 1.59 \\ \text { GSOR100291 } & 23.07 & 1.97 & 22.84 & 1.59 \\ \text { GSOR100302 } & 23.11 & 1.97 & 23.64 & 1.59 \\ \text { GSOR100328 } & 23.18 & 1.97 & 23.95 & 1.59 \\ \text { GSOR100165 } & 23.19 & 1.97 & 24.06 & 1.59 \\ \text { GSOR100028 } & 23.33 & 1.97 & 23.45 & 1.59 \\ \text { GSOR100112 } & 23.62 & 1.97 & 23.75 & 1.59 \\ \text { GSOR100308 } & 23.63 & 1.97 & 24.48 & 1.59 \\ \text { GSOR100332 } & 23.64 & 1.97 & 23.51 & 1.59 \\ \text { GSOR100287 } & 23.81 & 1.97 & 24.00 & 1.59 \\ \text { GSOR100196 } & 24.08 & 1.97 & 24.31 & 1.59 \\ \text { GSOR100226 } & 24.16 & 1.97 & 24.93 & 1.59 \\ \text { GSOR100307 } & 24.46 & 1.97 & 24.09 & 1.59 \\ \text { GSOR100149 } & 25.36 & 1.97 & 24.77 & 1.59 \\ \text { GSOR100077 } & 25.69 & 1.97 & 25.49 & 1.59 \\ \text { GSOR100014 } & 25.75 & 1.97 & 25.79 & 1.59 \\ \text { GSOR100253 } & 25.80 & 1.97 & 25.88 & 1.59 \\ \text { GSOR100141 } & 25.98 & 1.97 & 26.00 & 1.59 \\ \text { GSOR100053 } & 26.03 & 1.97 & 25.78 & 1.59 \\ \text { GSOR100064 } & 26.53 & 1.97 & 26.81 & 1.59 \\ \text { GSOR100072 } & 26.62 & 1.97 & 27.73 & 1.59 \\ \text { GSOR100163 } & 26.73 & 1.97 & 26.43 & 1.59 \\ \text { GSOR100058 } & 26.92 & 1.97 & 26.90 & 1.59 \\ \text { GSOR100121 } & 27.05 & 1.97 & 27.05 & 1.59 \\ \text { GSOR100326 } & 27.67 & 1.97 & 27.14 & 1.59 \\ \text { GSOR100187 } & 27.80 & 1.97 & 27.76 & 1.59 \\ \text { GSOR100236 } & 27.97 & 1.97 & 27.80 & 1.59 \\ \text { GSOR100303 } & 28.03 & 1.97 & 28.80 & 1.59 \\ \text { GSOR100311 } & 28.08 & 1.97 & 28.04 & 1.59 \\ \text { GSOR100325 } & 28.16 & 1.97 & 28.36 & 1.59 \\ \text { GSOR100247 } & 28.36 & 1.97 & 28.12 & 1.59 \\ \text { GSOR100004 } & 29.03 & 1.97 & 29.08 & 1.59 \\ \text { GSOR100182 } & 29.10 & 1.97 & 28.57 & 1.59\end{array}$




\begin{tabular}{lrrrr} 
GSOR100015 & 29.38 & 1.97 & 29.59 & 1.59 \\
GSOR100113 & 29.47 & 1.97 & 29.49 & 1.59 \\
GSOR100033 & 30.98 & 1.97 & 30.44 & 1.59 \\
GSOR100022 & 31.11 & 1.97 & 31.00 & 1.59 \\
GSOR100233 & 31.86 & 1.97 & 31.12 & 1.59 \\
GSOR100323 & 32.32 & 1.97 & 32.13 & 1.59 \\
GSOR100045 & 32.83 & 1.97 & 32.69 & 1.59 \\
GSOR100202 & 35.34 & 1.97 & 35.25 & 1.59 \\
GSOR100173 & 35.45 & 1.97 & 35.34 & 1.59 \\
GSOR100245 & 35.91 & 1.97 & 35.97 & 1.59 \\
GSOR100023 & 36.48 & 1.97 & 36.79 & 1.59 \\
GSOR100103 & 36.53 & 1.97 & 36.10 & 1.59 \\
GSOR100055 & 36.86 & 1.97 & 36.82 & 1.59 \\
GSOR100201 & 36.97 & 1.97 & 36.66 & 1.59 \\
GSOR100062 & 37.04 & 1.97 & 36.86 & 1.59 \\
GSOR100199 & 37.95 & 1.97 & 37.79 & 1.59 \\
GSOR100192 & 38.12 & 1.97 & 37.93 & 1.59 \\
GSOR100204 & 38.28 & 1.97 & 38.12 & 1.59 \\
GSOR100060 & 38.52 & 1.97 & 38.58 & 1.59 \\
GSOR100104 & 38.78 & 1.97 & 38.78 & 1.59 \\
GSOR100235 & 39.44 & 1.97 & 39.40 & 1.59 \\
GSOR100086 & 39.91 & 1.97 & 39.86 & 1.59 \\
GSOR100114 & 39.97 & 1.97 & 40.08 & 1.59 \\
GSOR100278 & 40.54 & 1.97 & 41.02 & 1.59 \\
GSOR100049 & 42.97 & 1.97 & 43.00 & 1.59 \\
GSOR100026 & 43.62 & 1.97 & 43.67 & 1.59 \\
GSOR100020 & 44.38 & 1.97 & 43.96 & 1.59 \\
GSOR100271 & 44.57 & 1.97 & 44.75 & 1.59 \\
GSOR100155 & 45.84 & 1.97 & 45.73 & 1.59 \\
GSOR100013 & 47.72 & 1.97 & 47.26 & 1.59 \\
GSOR100343 & 48.66 & 1.97 & 48.89 & 1.59 \\
GSOR100065 & 52.61 & 1.99 & 52.64 & 1.62 \\
KBNT_lpa1-1 & 3.15 & 1.97 & 2.96 & 1.59 \\
Zhe733 & 25.37 & 1.97 & 24.58 & 1.61 \\
\hline & & & &
\end{tabular}


Supplementary Table 4. Positions (cM) for pairs of chalk QTL identified in a two-dimensional genome scan with a two-QTL model (scantwo).

\begin{tabular}{llrr}
$\begin{array}{l}\text { Position 1 } \\
(\mathrm{cM})\end{array}$ & $\begin{array}{l}\text { Position } 2 \\
(\mathrm{cM})\end{array}$ & $\begin{array}{r}\text { LOD } \\
\text { P-value }\end{array}$ \\
\hline $1 @ 6.42$ & $\underline{1 @ 41.4}$ & 10.2 & $<0.001$ \\
$\underline{1 @ 31.42}$ & $\underline{2 @ 150}$ & 18.65 & $<0.001$ \\
$\underline{1 @ 31.42}$ & $\underline{4 @ 5}$ & 9.83 & $<0.001$ \\
$\underline{1 @ 31.42}$ & $\underline{5 @ 30}$ & 7.49 & 0.003 \\
$\underline{2 @ 150}$ & $\underline{4 @ 5}$ & 16.08 & $<0.001$ \\
$\underline{2 @ 150}$ & $\underline{5 @ 35}$ & 13.07 & $<0.001$ \\
$\underline{2 @ 150}$ & $\underline{9 @ 45}$ & 12.9 & $<0.001$ \\
$\underline{2 @ 150}$ & $\underline{11 @ 70}$ & 14.05 & $<0.001$ \\
$\underline{4 @ 5}$ & $4 @ 105$ & 6.89 & 0.009
\end{tabular}

Supplementary Table 5. Tests of all possible pairwise interactions, added one at a time to the multiple QTL model (addint). Significance levels of 0.01, 0.05, and 0.1 are indicated with the symbols “**”, "**”, and “.” respectively.

\begin{tabular}{|c|c|c|c|c|c|c|c|}
\hline QTL pair & df & $\begin{array}{l}\text { Type } \\
\text { III SS }\end{array}$ & LOD & $\%$ var & $\begin{array}{l}\mathrm{F} \\
\text { value }\end{array}$ & $\begin{array}{l}\text { Pvalue } \\
\text { (Chi2) }\end{array}$ & $\begin{array}{l}\text { Pvalue } \\
\text { (F) }\end{array}$ \\
\hline 1@1.4:1@31.4 & 1 & 39.69 & 0.16 & 0.16 & 0.69 & 0.39 & 0.41 \\
\hline $1 @ 1.4: 1 @ 106.4$ & 1 & 38.71 & 0.16 & 0.15 & 0.68 & 0.40 & 0.41 \\
\hline 1@1.4:2@148.0 & 1 & 27.60 & 0.11 & 0.11 & 0.48 & 0.47 & 0.49 \\
\hline $1 @ 1.4: 4 @ 2.0$ & 1 & 40.01 & 0.16 & 0.16 & 0.70 & 0.39 & 0.40 \\
\hline 1@1.4:4@104.0 & 1 & -9.58 & -0.04 & -0.04 & -0.17 & 1.00 & 1.00 \\
\hline $1 @ 1.4: 5 @ 32.0$ & 1 & 118.87 & 0.48 & 0.47 & 2.09 & 0.14 & 0.15 \\
\hline 1@1.4:9@33.0 & 1 & 33.51 & 0.14 & 0.13 & 0.59 & 0.43 & 0.45 \\
\hline $1 @ 1.4: 11 @ 69.0$ & 1 & 179.15 & 0.73 & 0.70 & 3.17 & 0.07 & 0.08 \\
\hline $1 @ 1.4: 12 @ 68.0$ & 1 & -16.13 & -0.07 & -0.06 & -0.28 & 1.00 & 1.00 \\
\hline 1@31.4:1@106.4 & 1 & 32.78 & 0.13 & 0.13 & 0.57 & 0.44 & 0.45 \\
\hline 1@31.4:2@148.0 & 1 & 435.42 & 1.80 & 1.71 & 7.92 & 0.00 & 0.01 \\
\hline 1@31.4:4@2.0 & 1 & 258.71 & 1.06 & 1.01 & 4.62 & 0.03 & 0.03 \\
\hline 1@31.4:4@104.0 & 1 & 36.05 & 0.15 & 0.14 & 0.63 & 0.41 & 0.43 \\
\hline 1@31.4:5@32.0 & 1 & 64.07 & 0.26 & 0.25 & 1.12 & 0.27 & 0.29 \\
\hline 1@31.4:9@33.0 & 1 & 52.54 & 0.21 & 0.21 & 0.92 & 0.32 & 0.34 \\
\hline 1@31.4:11@69.0 & 1 & 35.33 & 0.14 & 0.14 & 0.62 & 0.42 & 0.43 \\
\hline 1@31.4:12@68.0 & 1 & -28.01 & -0.11 & -0.11 & -0.49 & 1.00 & 1.00 \\
\hline $1 @ 106.4: 2 @ 148.0$ & 1 & 87.13 & 0.35 & 0.34 & 1.53 & 0.20 & 0.22 \\
\hline 1@ 106.4:4@2.0 & 1 & 116.88 & 0.47 & 0.46 & 2.06 & 0.14 & 0.15 \\
\hline 1@106.4:4@104.0 & 1 & 36.03 & 0.15 & 0.14 & 0.63 & 0.41 & 0.43 \\
\hline
\end{tabular}




\begin{tabular}{|c|c|c|c|c|c|c|c|}
\hline 1@106.4:5@32.0 & 1 & 20.98 & 0.08 & 0.08 & 0.37 & 0.53 & 0.55 \\
\hline $1 @ 106.4: 9 @ 33.0$ & 1 & 6.61 & 0.03 & 0.03 & 0.12 & 0.73 & 0.73 \\
\hline $1 @ 106.4: 11 @ 69.0$ & 1 & 122.26 & 0.50 & 0.48 & 2.15 & 0.13 & 0.14 \\
\hline $1 @ 106.4: 12 @ 68.0$ & 1 & 37.69 & 0.15 & 0.15 & 0.66 & 0.40 & 0.42 \\
\hline 2@148.0:4@2.0 & 1 & 148.40 & 0.60 & 0.58 & 2.62 & 0.10 & 0.11 \\
\hline 2@148.0:4@104.0 & 1 & 101.69 & 0.41 & 0.40 & 1.79 & 0.17 & 0.18 \\
\hline 2@148.0:5@32.0 & 1 & 3.81 & 0.02 & 0.01 & 0.07 & 0.79 & 0.80 \\
\hline 2@148.0:9@33.0 & 1 & 16.24 & 0.07 & 0.06 & 0.28 & 0.58 & 0.60 \\
\hline 2@148.0:11@69.0 & 1 & 209.77 & 0.86 & 0.82 & 3.73 & 0.05 & 0.06 \\
\hline 2@148.0:12@68.0 & 1 & 90.09 & 0.37 & 0.35 & 1.58 & 0.20 & 0.21 \\
\hline 4@2.0:4@104.0 & 1 & 9.79 & 0.04 & 0.04 & 0.17 & 0.67 & 0.68 \\
\hline 4@2.0:5@32.0 & 1 & 26.79 & 0.11 & 0.11 & 0.47 & 0.48 & 0.50 \\
\hline 4@2.0:9@33.0 & 1 & 196.61 & 0.80 & 0.77 & 3.49 & 0.06 & 0.06 \\
\hline 4@2.0:11@69.0 & 1 & 76.81 & 0.31 & 0.30 & 1.35 & 0.23 & 0.25 \\
\hline 4@2.0:12@68.0 & 1 & 123.81 & 0.50 & 0.49 & 2.18 & 0.13 & 0.14 \\
\hline 4@104.0:5@32.0 & 1 & -3.59 & -0.01 & -0.01 & -0.06 & 1.00 & 1.00 \\
\hline 4@104.0:9@33.0 & 1 & 147.58 & 0.60 & 0.58 & 2.61 & 0.10 & 0.11 \\
\hline 4@104.0:11@69.0 & 1 & 24.58 & 0.10 & 0.10 & 0.43 & 0.50 & 0.51 \\
\hline 4@104.0:12@68.0 & 1 & 168.67 & 0.69 & 0.66 & 2.99 & 0.08 & 0.09 \\
\hline 5@32.0:9@33.0 & 1 & 4.16 & 0.02 & 0.02 & 0.07 & 0.78 & 0.79 \\
\hline 5@32.0:11@69.0 & 1 & 256.85 & 1.05 & 1.01 & 4.59 & 0.03 & 0.03 \\
\hline 5@32.0:12@68.0 & 1 & 112.03 & 0.45 & 0.44 & 1.97 & 0.15 & 0.16 \\
\hline 9@33.0:11@69.0 & 1 & 116.16 & 0.47 & 0.46 & 2.05 & 0.14 & 0.15 \\
\hline 9@33.0:12@68.0 & 1 & 55.02 & 0.22 & 0.22 & 0.96 & 0.31 & 0.33 \\
\hline 11@69.0:12@68.0 & 1 & 107.93 & 0.44 & 0.42 & 1.90 & 0.16 & 0.17 \\
\hline
\end{tabular}

Supplemental Table 6. Fit of the full chalk multiple QTL model including 10 loci and two interactions.

\begin{tabular}{|c|c|c|c|c|c|c|c|}
\hline & df & SS & MS & LOD & $\%$ var & $\begin{array}{l}\text { Pvalue } \\
\text { (Chi2) }\end{array}$ & $\begin{array}{l}\text { Pvalue } \\
(\mathrm{F})\end{array}$ \\
\hline Model & 12 & 16135.14 & 1344.60 & 40.68 & 63.28 & $<0.001$ & $<0.001$ \\
\hline Error & 174 & 9364.68 & 53.82 & & & & \\
\hline Total & 186 & 25499.82 & & & & & \\
\hline
\end{tabular}

